\title{
Questioning Interdisciplinarity: Cognitive Science, Evolutionary Psychology, and Literary Criticism
}

\author{
Tony Jackson \\ English, North Carolina at Charlotte
}

\begin{abstract}
Cognitive science and evolutionary psychology show great potential as explanatory paradigms for a wide array of cultural products and activities, including literature. In some scholars' minds these two fields are emerging as the cornerstones of a major "new interdisciplinarity" that may well displace the relativistic interpretive paradigms that have dominated the humanities for the last few decades. Through a review of a number of recently published works, I assess the situation of these two fields in relation to the specific, currently reigning approaches to literary study as well as in relation to more general issues of academic literary interpretation. What do we have so far, and what can we possibly expect these essentially empirical-scientific disciplines to add to literary criticism? If cognitive science and evolutionary psychology are to become important in a truly interdisciplinary sense, then what kinds of claims will they need to make? Most important, how will the problematic but unavoidable distinction between nature and nurture be dealt with? Though the kinds of explanations offered in both fields can obviously enough be relevant to defining what literature is in relation to the human organism, how will the same kinds of explanations be involved in the actual interpretation of specific literary texts? For only an approach that provides new interpretive possibilities of actual texts can succeed on any broad level. After considering examples of current interdisciplinary work that, regardless of their other strengths, do not turn out to be significantly new and differ-
\end{abstract}

Research for this work was funded in part by a grant from the University of North Carolina at Charlotte. The author wishes to express his thanks to Meir Sternberg and the journal's anonymous reviewer(s) for their help with this essay.

Poetics Today 21:2 (Summer 2000). Copyright @ 2000 by the Porter Institute for Poetics and Semiotics. 
ent from previous paradigms, I consider an example that, to my mind, most strongly illustrates in a general way what the new interdisciplinarity will have to look like if it is going to succeed.

Literature has always been a rather special expression of mind and culture. This has remained the case even in the past three decades, when what in this essay I will call poststructuralist types of criticism have become dominant. Poststructuralism is our most recent form of relativism, and in some ways one of its historically most potent forms. When relativism overflows its dikes, it tends to wash away the presuppositions and boundaries that typically enable specialness. So as is well known, with the rise of deconstruction, Lacanian interpretation, French feminisms, New Historicism, much of postcolonial studies, and the like, the previously established specialness of literature seemed to disappear, or at any rate to be submerged (some would say drowned). And yet literature and the literary have remained in some ways more special than ever. Relativism pumps up the significance of rhetoric to the point that the literary becomes the type of all texts, and so of all knowledge. And with this, as Richard Rorty (1989: 80) has famously said, literary criticism becomes the type of all criticism.

But poststructuralism, like all relativisms, must inevitably find itself up against another, refortified dyke. Relativism cannot destroy its opposite - metaphysics, Platonism, rationalism, essentialism, whatever name we choose - but neither can relativism be destroyed (even Karl Popper [1985: 36] admits "a certain priority of irrationalism," his word for relativism). The two struggle together in their different ways, in the stormiest times making self-aggrandizing and brainless overstatements about the other, in calmer times challenging each other to become wiser and more self-aware. It may be that we have come upon another historical shift in the relations between these two attitudes, at least with respect to literary criticism. And the shift, if it comes to pass, may occur in part because of the powerful emergence in the last few decades of two related, empirical fields of study: cognitive science and evolutionary psychology.

Cognitive science, writes Steven Pinker (1994: 17), "combines tools from psychology, computer science, linguistics, philosophy, and neurobiology to explain the workings of human intelligence." Evolutionary psychology tries to explain the nature of human mental and cultural traits by bringing together cognitive science, human biology in general, paleontology, the theory of natural selection, and a long historical perspective. The two fields are separate but clearly related, the one explaining the nature of mind, the other explaining how the nature of mind came to be what it is. They often call upon one another. For instance, two natural questions to follow any dis- 
covery in cognitive psychology are: Why should this element of the mental architecture have ever happened in the first place? And what does this element's past mean for our present? And in some ways evolutionary psychology depends on cognitive science to provide the precise mental and cultural facts whose development needs to be explained. It seems impossible to deny that what these two fields have to say about the nature of human beings will bring about significant changes in a host of different disciplines. Here we will consider cognitive science and evolutionary psychology primarily in relation to literature and criticism.

But of course even to begin to discuss the literary in relation to claims from the empirical sciences gets us into an eternally unsettled realm of interdisciplinarity. For though literary criticism since the sixties has often tended to be interdisciplinary-bringing in philosophy, historiography, psychoanalytic theory, certain concepts from anthropology, and the like - it has for the most part kept itself separate from knowledge that would usually be considered scientific. This separation is hardly new. We will discuss it more directly as we go. For now, we may say that though there may be no reason for literary studies to incorporate or even attend to the findings of empirical sciences in general, this question still needs to be asked: Can the particular findings of cognitive science and evolutionary psychology be left out of the study of literature? If literature is a special expression of mind and culture, then can literary (or, really, any humanistic) study afford to keep itself separate from the area of research that is establishing itself as the scientific explainer of at least a certain level of mind and culture, and the area of research that is establishing itself as the scientific explainer of the history of mind and culture?

At first it might seem that, considering cognitive psychology in particular, we do have an interdisciplinary precedent of sorts. Psychoanalysis introduced itself to the world, originally at least, as a science of the mind, and many literary scholars took up this "science" with a certain zeal. From the beginning, of course, there were those in the humanities who disputed the scientific nature of Freudian concepts. But whatever the case with Freud himself, the emergence of Lacan removed this potential problem because Lacanian theory makes little pretense to any accepted idea of scientificity. In fact, the exact nature of psychoanalytic explanations, when compared to other kinds of explanations, remains rather an open question. Those (including myself) in literary studies who have used psychoanalytic concepts have for the most part simply never worried too much about their epistemological status with respect to the concepts of empirical psychology, biology, and the like. In our own literary-critical terms, psychoanalytic theory in one form or another has become a hegemonic discourse, so its most funda- 
mental presuppositions serve, typically, as given. Yet most psychoanalytic concepts arise, directly or indirectly, from claims about the nature of child development. At this point literary interpretations based on concepts of child development, on the process by which human animals become adult selves, can no longer simply ignore the findings of cognitive science, for that is where key truths in this area are being established. A similar situation exists with notions of language that follow poststructuralism: interpretive or theoretical claims that are based on poststructuralist notions of language and signs are wrong to ignore linguistics after Chomsky, Pinker, and others. And now we have seen a literary-interpretive turn to notions of the "body." Making claims about the body without being aware of what cognitive science and evolutionary psychology have to say can be a serious mistake because it is in these two fields, and perhaps others, that certain fundamental meanings of the body in relation to mind and self are being established. Having admitted, then, that cognitive science and evolutionary psychology will likely make some kind of difference to literary study, we may now ask just how much and what kind of difference.

This brings us to the focus of the present essay: the attempts, in the context of the reigning literary-interpretive paradigms, that have already been made to bring cognitive science, evolutionary psychology, and literary studies together. As we shall see, relations between the empirically oriented explanations and the reigning literary-critical paradigms are sometimes antagonistic, sometimes mutually reinforcing. In any case, given what has already been done, how can we think about the limits and possibilities of what may be done? For my own part, I find cognitive science and evolutionary psychology to be fascinating areas of study, but here I want to take on a willfully skeptical attitude toward both, at least as they may relate to literary criticism. I want to ask hard questions, the kind of questions that I think may legitimately be asked from the perspective of humanistic study as a kind of inquiry that is relatively distinct in method and aim from empirical-scientific inquiry. My goal is not to stifle the emergence of this "new interdisciplinarity" (Crane and Richardson 1999) but to help clarify the issues that will perhaps make any new work more compelling to a broad, nonscientific audience. In order to lay out certain basic problems and concerns, we will look first at a case for the general relevance of cognitive science and evolutionary psychology to the study of culture and mind. Then we will look at a number of examples of works that make specific links between cognitive science, evolutionary psychology, and literature. Along the way we will consider some basic problems of interdisciplinarity.

To begin, we need to consider why there is often not just a separation but an outright antagonism between contemporary literary (and other human- 
istic) interpretive theory and theory arriving from the empirical sciences. For as has been recently discussed, though literary study has often welcomed other disciplinary approaches and concepts, this welcome, except in a few cases, has not extended to cognitive science and evolutionary psychology (Crane and Richardson 1999: 123; Easterlin 1999: 131). Why not? The general critique by any poststructuralist position of anything like positivist "fact" hardly needs mentioning. But with respect to evolutionary psychology and cognitive science, there is a specific quality of this critique that most matters. Perhaps the best way to get at that quality is to examine what those who come from the empirical-science side have to say. The sometimes antagonistic, sometimes condescending attitude of poststructuralist critical positions toward scientific knowledge has been felt powerfully by many of those who would bring natural selection and cognitive science into the humanities and social sciences. In fact, it seems that in arguing for these empirically based claims about psychology or cultural affairs, scholars often feel a need to begin with a more or less wholesale rejection of poststructuralist conceptuality. And this is true in more than just the literary arena. For example, Jerome Barkow, Leda Cosmides, and John Tooby open their important volume on evolutionary psychology, The Adapted Mind (1992), with a very long polemic against the reigning interpretive paradigm in the social sciences, a paradigm that they feel has brought disaster to the discipline as a whole. In fact, I mention The Adapted Mind first because its opening chapter makes by far the most detailed and informed attack on what it takes as its opposition. The book sets itself against what is called the Standard Social Science Model (SSSM). Explanations within the SSSM are grounded on the idea that culture and language offer the only really relevant explanations of human social and psychological being. To put it another way, the SSSM assumes, whether it thinks of itself this way or not, that in fact "human nature is an empty vessel, waiting to be filled by social processes" (Barkow et al. 1992: 29). To look at a similar claim in the realm of literary study, we find Mary Thomas Crane and Alan Richardson (1999: 129) arguing that Derrida's view of the world as thoroughly textual "can be seen as postulating what amounts to a particularly sophisticated version of the behaviorist refusal to consider the systems and processes that produce behavior." These claims have merit.

Though the SSSM and poststructuralism obviously have their own separate foci and histories, conceptually they both take off one way or the other from some version of the idea that culture or symbols or language or narrative, and so on, precede the real. As is well known, a fundamental tenet of all poststructuralist positions is that signifiers precede in a crucial way any signified; that is, discourse or language or, more generally, representation 
always precedes and determines whatever we may have of knowledge and experience. Further, the signified, which is what we most want, is always ultimately unreachable. Given this conceptual "ground," other ideas and conclusions follow. Once it has been accepted that representations determine reality and the self, that there can be no reality, no human being, without some enabling symbolic order, then it can easily follow that the true nature of even biological organs and processes must be determined by culture and signs. Therefore, what really matters about biology, if biology is seen to matter at all, is not so much the truth or falsity of what it says but rather the kinds of discursive forces that are producing "biology" as a discipline whose nature is to see things in certain ways. What matters about the body is the way its presence in the world is being determined by language and other cultural systems of signification. The attitude about biology that is typical of the SSSM is also common in the broad array of literary and cultural studies that has emerged in the humanities since the sixties, and this same basic attitude has been taken up with respect to some other empirical sciences as well.

Further, we can find a paradoxical suspicion or rejection or at the least a neglect of any Darwinian evolutionary explanation of culture and psychology, which is what most concerns the writers in The Adapted Mind. In fact, there is an inclination in the humanities and to some degree in culture at large to equate any evolutionary explanation of culture and mind with Victorian-style social Darwinism. Unfortunately, this equation is often based on what amounts to a Victorian rather than a contemporary understanding of evolutionary theory. Evolutionary explanations of whatever kind are unlikely to imply the specific behavioral determinism that many people fear. As the introduction to The Adapted Mind takes great pains to show, neither " 'biology,' 'evolution,' 'society,' [nor] 'the environment' directly impose behavioral outcomes, without an immensely long and intricate chain of causation involving interactions with an entire configuration of other causal elements. Each link of such a chain offers a possible point of intervention to change the final outcome" (Barkow et al. 1992: 39). Nancy Easterlin (1999: 137), writing of all this in relation to literary theory, makes the point that "the contemporary view of evolutionists is that our learning processes are governed by instructions for organizing information from the environment - that it is general forms of thought, not specific content that is biogenetically given" (137). In other words, evolutionary psychology does not imply a hard-core determinism and does not offer the entire explanation for human behavior. Neither does cognitive psychology. And yet inevitably the question of determinism is the one that most matters. We will consider this idea at more length below. But in any case, given the com- 
mon antagonism toward evolutionary explanations of culture and mind, and given that evolution in one way or another is a central concept in all the biological sciences and also tends to be important in cognitive science, those who want to bring evolutionary psychology and/or cognitive science into the humanities often seem to feel that to make their points, they must first set out to destroy the opposed explanatory paradigm. Whether the dike meticulously built in the introduction to The Adapted Mind successfully holds back the waters of relativism and brings salvation to the social sciences is open to discussion, and for the purposes of this essay that success is not so important. What matters is that the editors, all quite prominent in the field of evolutionary psychology, felt the need to write their introduction in the first place.

What we have just described with respect to The Adapted Mind - the need to begin an argument with the destruction of the poststructuralist opposition - is also the case with two of the most recent attempts to bring cognitive science and evolutionary psychology directly into the realm of literary interpretation: Joseph Carroll's Evolution and Literary Theory (1995) and Robert Storey's Mimesis and the Human Animal: On the Biogenetic Foundations of Literary Representation (1996). Both of these writers have high praise for The Adapted Mind, and both begin and end with polemical attacks on poststructuralist interpretive positions. To turn to Carroll's book first: his introductory exposition and rejection of poststructuralism is, I find, exemplary (not meaning bad or good here) in a number of important ways. First, the intensity of his rejection reveals a common feeling among many who reject poststructuralism. Writers such as Storey and Carroll seem to feel that their own claims must disallow any significant truth arising from the generally relativistic grounds of recent interpretive paradigms in the humanities. This appears to be a defensive reaction arising from the fear that if poststructuralist conceptuality is true, then all hope of objective, scientific knowledge is lost. Now in one way this reaction is not wholly unwarranted. It is easy enough to pull out statements from the famous poststructuralist writers that will appear to thinkers such as Carroll to disallow the truth in some general sense. This is, however, to interpret poststructuralism as nihilism, which is not really an accurate understanding. Poststructuralism is a version, perhaps one of the most potent versions, of relativism, and therefore it is not nihilistic: it does not claim, at its best, that there is no truth or meaning, only that there is not a certain kind of truth or meaning (cf. Jackson 1995).

To show how this miscomprehension can work, we may look at a quote from Foucault that Carroll brings in to explain poststructuralist "textualism." The quote from Foucault reads: "If interpretation can never be brought to an end, it is simply because there is nothing to interpret. There 
is nothing absolutely primary to interpret, because at bottom everything is already interpretation" (quoted in Carroll 1995: 4; italics mine). Now if we take the first sentence alone, it can seem to make a nihilistic claim: human reality in general is a constant rehashing of nothing. But the second sentence makes a crucial qualification. As in all properly relativistic (and thus properly poststructuralist), rather than nihilistic, claims, we cannot really posit the case of some simple, self-consistent "nothing" from which arises what we have of the world. Such a concept would be a straightforward negation, and one reason poststructuralist positions are both true and difficult to grasp is that they try not simply to negate. So there is always "something" that anchors interpretation. There is not, however, something that will anchor interpretation in the way that Carroll would most want. Carroll quotes the words that most matter but of course does not seem to notice them.

This is not to say that Carroll is entirely oblivious to those points when poststructuralists try to head off the nihilist misinterpretation. But when such thinkers make plain that they are not nihilists, Carroll accuses them of stating truisms: claims that are so obviously true they need not be made. For example, he quotes Stanley Fish's statement that it is impossible ever to hear an utterance in some kind of entirely raw, noncontextualized way: "To so hear [an utterance] is already to have assigned it a shape and given it a meaning" (quoted in Carroll 1995: 62; Carroll's italics). Carroll then includes Fish's qualification: "I [Fish] am not saying that one is never in the position of having to self-consciously figure out what an utterance means" (quoted in ibid.: 62; Fish's italics). This latter may appear a truism to Carroll, but Fish must state it very plainly in hopes of keeping a reader from going away with a seriously incorrect (that is, nihlistic) idea of what he is trying to say. Fish's hope fails with Carroll. I give only this one example, but there are precisely similar others involving Foucault (ibid.: 62) and Derrida (ibid.: 63). Carroll's explanation and rejection are exemplary because he does notice these key points of argument but can only see them as truisms.

Having made plain the important presence of this conflict, we will put it aside for a moment. The question now is: Whatever the outcome of Carroll's attack on poststructuralism, what does he offer in place of what he rejects? For unlike his relativist opposition, which is committed to what he calls "parasitic negativity" (244), Carroll cannot stop with only a critique of the reigning paradigm. From considering his ideas, what will we learn about literature and interpretation that we had not known before? In bringing evolutionary-psychological considerations to literature, Carroll thinks of himself as proposing a new paradigm, one whose "foundational principles answer more adequately to the natural order within which, as the paradigm itself proposes, all texts are contained" (45). He argues that 
"knowledge is a biological phenomenon, that literature is a form of knowledge, and that literature is thus itself a biological phenomenon" (1). He sets out to "substantiate the relevance of evolutionary theory to literary theory in a variety of quite definite ways" (1). "I construct," he writes, "a critical system that integrates evolutionary theory, both classical and contemporary, with critical concepts from traditional literary theory, and I use this critical system as the framework within which to analyze and oppose the poststructuralist assumptions that now dominate academic literary studies" (1). For Carroll, evolutionary theory is going to save literature and criticism from poststructuralism.

But what we actually get does not really turn out to be so terribly innovative. In setting up his initial definitions of literature, Carroll says that "all human experience is ultimately reducible to neurochemical terms." And if this is so, then "the subject matter of literature is continuous with that of physics and chemistry" (104). So we might expect some fairly scientific explanation of literature and interpretation. But he goes on to say that human experience has "cognitive properties that emerge only at levels of organization higher than those with which physics and chemistry are concerned, and it is these higher levels that are the appropriate subject matter of literature" (103-4). Now this last statement is much more true to what we would hear from most cognitive scientists or evolutionary psychologists. It is not common to make the straightforward claim that culture and psychology are in any simple way biological phenomena. And yet this qualification can easily go on to undo Carroll's project. First, this kind of admission begins to open the door for an understanding of literature and interpretation that has no significant relation at all to interpretive approaches that are rooted in biology or physiology of whatever kind. It will be easy enough to say that cultural products and actions are just those products and actions that emerge at a level of organization higher than (or at least significantly different from) the biological, and therefore biology and evolution are at best only tangentially relevant to their study. Beyond this, though, it turns out that the higher-level, appropriate subject matter is simply "the subjective quality of experience" (106). Literature differs from other arts and the sciences "in the use of words as a medium." Further, it "concerns itself with the aesthetic properties of its medium" (106). The "aesthetic qualities of composition are perceptible even in silent reading, but they become most apparent when we read aloud with sufficient care to register phrasal rhythms and inflections of tone and volume" (107). Carroll evidently feels he is saying new things here. He feels that he is proving the biological basis for the traditional (that is, pre-poststructuralist) notions of literature and thereby disproving the claims of poststructuralist interpretations. But poststructuralism would 
agree with most of these ideas; the disagreement would involve what actually happens with literature in specific cultural contexts. Unless biologically based analyses are going to explain literary affect in toto, then the realm of history, desire, and politics will inevitably come into play. So if Carroll is not going to write some new definition of these very basic terms, he will not have done much to change our understanding of literature. In fact, these statements tend to be truisms. Carroll does apply his ideas in more specifically interpretive ways. He offers readings of George Eliot's major novels, of Portrait of a Lady, and of Heart of Darkness, among others, and devotes much time to Walter Pater's Marius, the Epicurean. His interpretations are worth reading in a general sense, but as with his claims about literature per se, he does not really offer us anything new. And it is not clear that Darwin or biology have made any interesting difference in getting at the interpretations he does provide.

At one point in his explanation of literature in relation to evolution, Carroll turns to the writings of Derek Bickerton, a prominent thinker on language, evolution, and consciousness. Taking off from Bickerton's Language and Species, Carroll says that "the conceptual structure of syntax is lodged in neurological structures," so variations "in syntax generate variations in physical sensation, and the latter are all susceptible to aesthetic organization" (106). That is, we react to the arrangement of words not just because of literary or linguistic experience but also because of our biology. This is, in fact, a standard kind of claim at this point in bringing evolutionary theory and cognitive science to bear on actual elements of literature. As a claim it is interesting enough in its own right (though Carroll does not do too much with it); what matters here is that this kind of claim leads us to the skeptical questions that will likely be asked of anyone who will explain literary response as one way or the other a function of biological processes: at what level of explanation will biology or whatever other empirical science stop being primary? Of cognitive science, Crane and Richardson (1999: 129) write that while it "does give a large role to the shaping power of culture, it also stresses the role of innate mental dispositions and innately constrained cognitive procedures that hold across cultures and historical eras." Nancy Easterlin (1999: 138) speaks of the field of "bioepistemology," which focuses "epistemological questions on how the naturally selected brain operates flexibly within parameters that both enable and constrain knowledge; it thus provides a crucial starting point for those who study the artifacts of human culture" (138). Even with these qualified claims about the importance of biology, if what Carroll has said about syntax is true in this way, then what? Taking up my role as skeptic, I ask, "How will it matter for interpretation?" Since science establishes facts that, in principle, remain true apart from 
time and place, then scientific claims about self and culture always run the risk of being taken as normative, as the hardwired and therefore "right" way, which is why the worry over social Darwinism always arises. Unless we are to make only the trivial claim of simple difference from the norm, will we say that a given language use is wrong or creative or false because it departs from a neurological structure? Will we construct categories of syntactical forms that can be depended upon to produce specified biological responses? Will we assess good literature by measuring neurological responses to certain syntactical forms? Most of the writers who have stepped into this interdisciplinary arena would say no to these questions. Explicitly or implicitly, they always leave room for the work of culture itself as an active force in human life. But then this question arises: If we are not going to explain cultural productions in relation to biological facts, then will we need cognitive science and evolutionary psychology at all for the practice of what is generally considered to be literary study? Of course, there is no reason to assume that things must be either/or, either biological or not. But in any case, in what way will this affect what we say about specific literary meanings? We will return to these questions below.

Remaining for the moment with those who take up cognitive science and evolutionary psychology as weapons for the destruction of poststructuralist theory, we turn to Robert Storey's Mimesis and the Human Animal. Storey praises both Carroll's book and The Adapted Mind. Like these two predecessors, he opens his book with an attack on what he can only see as the "logical bankruptcy" of poststructuralism (xv). With respect to psychoanalysis in particular, he makes the case that it has an "empirically unconstrained nature," that it is "immune to falsification," and that the "infinite flexibility" of its interpretive rules allows anything to be said (xxi). Of poststructuralism or relativism more generally he asks, if context determines truth and there is no absolute value by which to make judgments among truth claims, then why should the relativist's own claims be taken as true (4)? These are standard objections to which I myself have elsewhere responded (Jackson 1995), but they need not concern us here. Nor need Storey's often bitter attacks on a number of the more famous poststructuralist critics. Suffice it to say that although there is no denying the scorn and condescension heaped on the opponents of poststructuralism, Storey hardly makes matters better by treating his opponents in the same way. In any event, like Carroll and the writers of The Adapted Mind, Storey sees his project as what is needed to reverse the corruption brought about by relativistic interpretive positions.

To turn to his ideas, Storey devotes the first half of his book to explaining some of what has been discovered in recent decades in cognitive scientific research and in evolutionary psychology. He taps into either or both disci- 
plines at various points later on in his actual interpretations. He has done a lot of homework in this respect, much more than most students of literature are likely to undertake. In general, aside from his unnecessary stabs at his opposition, this is a good introduction for literary scholars to useful findings in both of the fields in question. But, interestingly, Storey's exposition does not really quite achieve what he most wants: the ruination of poststructuralist conceptuality.

Above I have briefly recapitulated the poststructuralist understanding of signs, representation, discourse, and language. If poststructuralist conceptuality and its offspring are to be undone in any serious way, then one crucial place to begin will be, precisely, with the understanding of signs, representation, discourse, and language, for all its other claims and conclusions may be said to follow after this initial understanding. Crane and Richardson stress this fact. Given the work of cognitive linguistics in the wake of Chomsky, literary theorists, they write, "can be expected to feel the pressure to begin rethinking received notions like the arbitrariness of the linguistic-conceptual field" (Crane and Richardson 1999: 137). Storey does deal with the language issue, but, oddly, he turns to a psychoanalytic theorist for support. Citing at length some research by Daniel Stern, Storey explains how a human infant comes into language, how at first we have what is called the "amodal global experience ... through which the world of the pre-linguistic subject is grasped and unified," and how that prelinguistic unity is then "fractured' by the advent of language" (71). In a block quote from Stern we read of a preverbal infant's perception of a patch of sunlight on a wall. In order for the child to continue with its "amodal" experience, with this

highly flexible and omnidimensional perspective on the patch, the infant must remain blind to those particular properties ... that specify the sensory channel through which the patch is being experienced. Yet that is exactly what language will force the child to do. ... Words . . . separate out precisely those properties that anchor the experience to a single modality of sensation. By binding it to words, they isolate the experience from the amodal flux in which it was originally experienced. (Storey 1996: 71)

With very little adjustment, anyone who has studied Lacan or Kristeva (to name only two) will readily recognize this explanation. Though the disciplinary context entails slightly different explanatory forms, conceptually this description of how a self is formed with the advent of language is more or less identical with the linguistically based psychoanalytic theory that takes off primarily from Lacan's revision of Freud. Given Stern's own training, this is not surprising, but it is surprising that his explanations would ap- 
peal to Storey. Stern goes on to say that the linguistic version of experience "becomes the official version, and the amodal version goes underground and can only resurface when conditions suppress or outweigh the dominance of the linguistic version" (quoted in ibid.: 71). This is clearly a version of Freud's primal repression and is also clearly related to Lacan's revision of Freud. Kristeva (1986) specified the official "linguistic version" (wrongly, I would say) as patriarchal and argued that truly poetic language occurs as a kind of revolution: the underground version erupts from within the dominant linguistic forms, thus giving us the revolution in poetic language.

Storey is aware to a degree of these implications. Having committed himself to what he sees as a scientifically established view of the entry into language that is so very much like the poststructuralist one, he needs, if he is to rout the opposition, to remove the implications of the essential arbitrariness of (linguistic) signs. This is because he has basically accepted the idea of the self as a function of language; if language is essentially arbitrary and the self is a function of language, then the self will be, in a key sense, also arbitary. Consequently, the decentered self that has been described by so much of poststructuralist writing will remain in place, as will, presumably, the literary-interpretive paradigms that go along with it. He tries to offset these implications by turning to the work of George Lakoff, Mark Johnson, and Mark Turner. These three, together and separately, have done pathbreaking work explaining how "metaphor is not merely a linguistic mode of expression" but is, rather, "one of the chief cognitive structures" that enable us to have meaningful experience at all (Johnson 1987: xv). Since "metaphor resides in thought, not just in words," then human thought is itself ultimately biological (Lakoff and Turner 1989: 2). Now on the one hand this is a truism. Barring supernatural explanations, thought cannot ultimately be anything but biological. But the kind of claims put forth by Lakoff, Johnson, Turner, and Storey want to anchor meaning absolutely by embedding it in biology. Even though they would all deny this, even though they would use the qualification constrain to describe how biology affects meaning, the outcome of what they say is the end of the play of signs, the positing of a transcendental signifier. Paul Miers has pointed out that Lakoff's claims about metaphor require that we forget the significance of the necessary difference between a signifier (he uses the word symbol) and its signified. If we arrive at some case in which there is no difference between a metaphor and thought, "then thought does not require the mediation of symbol because the meaning is simply given; if [metaphor and thought] are different, then a space is opened between the original and its representation and thought can only know the original by way of the representation" (Miers 1992: 968). Storey seems to assume that just bringing in these ideas will automatically 
kill off the conclusions poststructuralism draws from its generic understanding of signs and signification. But it is not clear that this will follow, because the issue of arbitrariness still holds on the level of language itself. ${ }^{1}$

As with Carroll, we may ask of Storey's work what new insights it provides us, and especially what new insights into the actual interpretation of literature. Storey brings cognitive-scientific research into definitions of tragedy and comedy and an interpretation of Iris Murdoch's A Fairly Honourable Defeat. On the way to these more literary applications, Storey taps into what has become a potent, now almost commonplace explanatory term in cognitive-scientific thought: narrative. Any number of influential writers (for instance, Roger Schank and Robert Abelson [1977], Turner [1996], Daniel Dennett [1991], Jerome Bruner [1990], Pinker [1997]) have taken up narrative as a key term in their explanations of the nature of cognition and mind. Mark Turner (1996: 4-5) writes that "narrative imagining - story - is the fundamental instrument of thought. . . . It is a literary capacity indispensable to human cognition generally." As Storey says, narrative is now seen as a key "instrument of social adaptation . . essentially an enculturating agent" (103), as "the mind's 'primary psychodynamics," "as the "deep grammar' of literature itself” (113). Borrowing at length from Bruner, Storey writes that narrative "is not, as many theorists have maintained, so much 'story' as an innate way of knowing, essentially as prelinguistic in its operations as conceptualization has proven to be" (84). But the use of narrative in this way brings up a general issue that will likely be relevant when cognitive science or evolutionary psychology and literary study are brought together. To what extent will arguments in a given discipline be expected to include a full knowledge of the key terms imported from other disciplines? This may be an unavoidable problem in interdisciplinarity. It is starkly illustrated in the 1994 roundtable issue of Stanford Humanities Review: "Bridging the Gap: Where Cognitive Science Meets Literary Criticism." There, Herbert Simon, the Nobel laureate in psychology and computer science, offers an essay on a cognitive approach to literary criticism, and this is followed by responses from some thirty-three scholars, a number of whom are in literary studies. One problem with Simon's essay that is plainly clear to any literary scholar gets stated (in a very ungenerous way, given the context) by respondent Suvir Kaul, who says that Simon's

1. The issue of signification may well still be the nexus of difference in all this. On the one hand, we have what Steven Pinker and others call "mentalese": the nonlinguistic thought that can be inferred to exist prior to and apart from linguistic expression. Mentalese would appear to remove the most serious implications of the arbitrariness of the sign. But then Pinker (1994: 152) also states unequivocally that the "relation between [a word's] sound and its meaning is utterly arbitrary." So arbitrariness still matters, but to what extent? And what would be the "meaning" of a thought apart from the language by which the thought was made knowable? 
"account of all that passes for literary criticism is so ill informed" that it is hardly worth discussing. Simon, he says, needs to "be much more aware of the specialized vocabularies of literary criticism than he has chosen to be" (Kaul 1994). ${ }^{2}$ In some ways Simon, however respected for his many accomplishments, was not the ideal choice for this roundtable at this time. He is primarily associated with what Crane and Richardson (1999: 124) call the "first phase of the cognitive revolution." Another generation of thinkers in this area has come along, and they would be somewhat less vulnerable to the kind of charge leveled by Kaul. But only somewhat less vulnerable. Cognitive-scientific appropriations of "narrative" typically still run into the same kind of problem that arose with Simon's discussion. There often seems to be a tendency simply to take up the term narrative as if it is a straightforward, unproblematic category, which is to say there seems to be a tendency to ignore (or simply be unaware of) much of what has been said about narrative in the past thirty years.

Narrative has of course been a central preoccupation in much poststructuralist interpretation. Further, the turn to narrative has been directly related to the implications of the arbitrariness and essential importance of the sign, to the idea that representation or discourse must precede and in an important sense determine the real. In fact, I would argue that narrative, especially as understood by Peter Brooks, Hayden White, Fredric Jameson, Roland Barthes (all four mentioned by Storey), and the like is itself what I am calling a poststructuralist concept. For many of us, "narrative" now includes such things as the paradoxical relations between story and discourse (Culler 1981), an unstable temporality (Brooks 1985; Jackson 1994) and the disjunctive relations between imaginary, real, and ideal narrators and audiences (Rabinowitz 1977; Prince 1981). Typically, none of these aspects of narrative gets taken up when the term is brought into cognitive science or evolutionary psychology. ${ }^{3}$ In fact, as David Herman (1999: 25) has said of Turner's The Literary Mind, narrative or story or parable or whatever similar word "functions as a kind of primitive, undefined term." We are not provided with "a principled account of what is arguably the root concept of" studies of this kind (ibid.). Literary scholars may not have rendered the once-and-for-all definition of narrative, but nonetheless, to use narrative as a key term and ignore what has been said of it in literary studies is run-

2. Kaul provides a good example of why those opposed to poststructuralist approaches may justifiably feel some resentment. He opens his response by saying that "Simon's conversational tone is perhaps the most engaging element of his paper, and perhaps his pared-down simplicities and egregious generalizations are made possible and justified only by his unremittingly unscholarly manner" (Kaul 1994). This kind of condescension is unfortunately too common.

3. A worthwhile exception here may be found in Polkinghorne 1988. 
ning exactly the same risk as using body as a key term and ignoring cognitive science.

Storey, a literary scholar, is at least somewhat aware of these implications. Following Bruner (1990), he identifies "ambiguity . . . as a defining characteristic of narrative" (82). In other words, ambiguity is to narrative as it is to language: narrative, like language, works at all only because it is ambiguous. But Storey holds that "ambiguity as a phenomenon of narrative accounts seems to go rather deeper" than Bruner claims. In fact, the "purer" the narrative, the more "successfully it will resist explanation and so reside more elusively in the realm of the ambiguous" (83). Storey admits that he has elaborated "a paradox" here, but he does not admit that it is classically poststructuralist: the nature of identity is such that the closer a "thing" gets to being just what it wants to be, the further it also gets from being itself. He then tries to move out of the paradox: "Only when narrative thought is re-presented, usually through the usefully (if meretriciously) stabilizing medium of language, does it acquire the 'ambiguity' that I have ascribed to it" (84). The paradox remains, as far as I can tell, only now it is displaced to language, exactly where so many poststructuralist thinkers have located it.

And what of Storey's ideas about literature and interpretation? Though he has good, useful things to say, he does not really offer much that sounds revolutionary. Taking narrative as a term in much the way Turner does, Storey says that in narrative we "can have the pleasure of the emotions that accompany loss or injury while remaining certain that [we] will suffer the real effects of neither" (115). Narrative "helps ensure the cohesiveness of a culture by bringing the potentially disruptive in line with social norms" (114). In narratives, "paradigm scenarios ... educate the young in the practices of their culture" (125). Narrative educates "readers' sympathies" (128). "Understanding is easier in literature than in life because the reader has been relieved of physical involvement and can rehearse the dynamics of human transactions with both emotional intensity and detachment" (128). Now all of this seems entirely believable, but, as with Carroll's claims above, it is hardly setting up a new paradigm. Many poststructuralist understandings of literature would deny none of this as stated, but, again, would ask about the actual operations of texts in real historical contexts. What kind of cultural cohesiveness is being ensured by a particular text? Who or what in a given text is being represented as disruptive and from what point of view? Who in a given text gets favored and who disfavored by social norms? Do the cultural practices in which the young are being educated involve an unapparent but systematic devaluation of certain groups? From the way Storey says all this, it is as if he assumes that social norms are as univer- 
sally similar as biological facts. But most people would say this is not the case. To put it another way, if evolutionary psychology and cognitive science are not going to explain everything about, say, "the dynamics of human transactions," then other kinds of interpretive positions will still make a difference.

In turning to the concept and importance of tragedy as a literary form, Storey discusses cognitive scientific and evolutionary claims about the universality of certain emotional responses, especially in relation to kin. $\mathrm{He}$ offers Antigone as "perhaps the richest example of the whole of the tragic literature" (142), and his interpretation of Antigone's famous dilemma about family versus state obligations is exemplary. Antigone, he says, does not really go through a "reasoning" process in deciding to bury her brother in defiance of Creon. "That position has been prepared by natural selection, meaning that the emotional options among which she must choose have already been invested with a certain relative weight" (143). Genetically speaking, it would make "perfect fitness-enhancing sense" to value a brother over a husband (143). The problem, though, has to do with the conflicting social and political context. On the one hand, this would seem a likely way to bring evolutionary psychology and literature together. We have an interpretation that discovers a conflict between universal biological priorities and particular cultural practices. But still, if the interweaving of evolutionary psychology and literary interpretation are to matter, presumably we will have to hear new interpretations. What Storey says seems true enough, but except for the fact that it is now backed up by evolutionary psychology, it hardly needs to be argued for. Who would deny that Antigone's dilemma involves a conflict between immediate family obligations and obligations to civil authority? Much the same could be said regarding Storey's reading of Murdoch's novel. It is a reasonable, well-written reading, but unless interpretations are to be valued not for their insight into literary texts as cultural artifacts but simply because they base themselves in evolutionary psychology or cognitive science, then these interpretations, however true, may not be very interesting to very many people. I am not saying Storey is not a good literary reader: he is. But when he is at his best in reading, he seems least to need the science, and when he most recruits the science, he tends to give his least interesting readings.

We have faced a similar situation with both Carroll and Storey's books: though they promise something strikingly different, what we actually get seems in fact quite familiar, except for the grounding in evolutionary psychology and cognitive science. Herbert Simon's essay, mentioned above, has the same problem, though for different reasons: he is, after all, not a literary scholar, so we would not have the same expectations of him as we 
might of Carroll and Storey. Frederick Adams (1994) the first respondent to Simon's piece, says outright that it does "not seem to add things that are new or more precise than any literary critic would have known." The same may be said of Steven Pinker's (1997: 538-43) explanation of literature in How the Mind Works; Pinker is very smart and a very good writer, and everything he says is true, but he tells us nothing that is not already widely known.

All this brings us back to our larger question: How in general might we expect cognitive-scientific and evolutionary-psychological understandings of literature to matter? It seems to me there are two most basic possible areas of relevance. First, given the facts that these disciplines are laying out certain universal attributes of the biological human animal and that one way or the other these attributes strongly (though not fully) determine the nature of the social and psychological human animal, then it will necessarily be the case that these disciplines can (and probably should) offer their own explanations of literally any given cultural or psychological artifact or action. It is this aspect of both cognitive science and evolutionary psychology that make them so impressive to consider (and that often makes evangelists out of their supporters). We may expect, then, that these empirical-scientific fields will explain what literature is by showing how it operates in relation to cognition and evolution. The second major possible area of relevance would have to do with explaining the meanings of specific examples of literature, that is, with interpretation itself.

Up to this point it is primarily in the first area that we have seen the most interesting work. Carroll and Storey do this, but not really in ways that tell us much we have not already known about literature. In a way they claim that literature is what people have thought it is since Aristotle, but now we know that this is biologically true. But we do have the work of Turner, Lakoff, Johnson, and Bruner, and so on, all of whom make convincing and productive claims. These latter are in my mind examples of interdisciplinary success of a certain kind, though as I have been trying to show, there are problems with what they say. Another example of success in this area, worth mentioning because it models a certain kind of approach, is Ellen Spolsky's Gaps in Nature: Literary Interpretation and the Modular Mind (1993). Spolsky's book also matters because it shows that there need not be any categorical antagonism between poststructuralist and cognitive-scientific concepts. Where Carroll and Storey drew largely from evolutionary psychology and to a lesser degree from cognitive science, Spolsky's book makes direct use of specific findings in cognitive psychology. As I stated above, cognitive science is establishing empirical facts about cognition, and cognition is one way or another central to the mind, to self-consciousness. So a given cognitive-scientifically based explanation of how the mind works will in principle have implications for all of culture and psychology. Therefore, 
as new explanations of mind become sufficiently persuasive, we may expect new explanations of cultural artifacts and activities to come along that take into account what has been discovered about culture and psychology.

Spolsky takes one of the currently compelling explanations of how the mind must work and explains not literature per se but literary theory in relation to that particular explanation of mind. She brings in interrelated works by Marvin Minsky, Ray Jackendoff, and Jerry Fodor that address the idea of the mind as a collection of biologically constrained cognitive modules that carry out different, specific types of tasks. This layout comes with various benefits as well as drawbacks, only one of which need concern us here. An outcome of the modularity explanation is that there is no necessity for some central coordinating entity of any kind to bring the various modules into a unified, singular presence. There is coordination between the modules, but only to a degree. What matters to Spolsky is that cognition is both enabled and plagued by gaps - "incomplete enregistration between modules," she calls them - that are entailed by the very fact of modularity (112). In other words, as with arbitrariness in language and ambiguity in narrative, modularity works as it does because of gaps. With this in mind, her book argues "that the difficulties, or perhaps the impossibility ... of maintaining the kind of unified perspective traditionally thought of as centered in an individual mind or soul are not logical or philosophical difficulties but are, in fact, material. They are an inevitable consequence of brain architecture and the structure of consciousness it produces" (12). Further, "brain theory confirms that the inadequacies of language are not merely matters of local inadequacy - gaps that a larger vocabulary or a new metaphor could fill. The phenomenon of incommensurable readings is not accidental; it is genetically built into the brain" (5). Given all this, she claims that "a culture's most powerfully imaginative texts are understandable as the heroic efforts of particularly responsive minds, goaded by the inevitable asymmetry and incompleteness of mental representation to vault the gaps in brain structure thus surpassing the limitations of the biological inheritance. The mind itself can hurt you into poetry" (2). Plainly enough, Spolsky is finding empirical support for the idea of consciousness that has been most thoroughly explored in the realms of poststructuralist or, as she calls it, postmodernist thought. It is not just coincidence, she writes, that this kind of claim has become possible just "as postmodernism has begun to be widely understood beyond the esoteric circles of its origins" (36). She has some good company in this respect, most famously Daniel Dennett in Consciousness Explained (esp. chap. 8), and we must wonder if Carroll and Storey miss this at least in part because they are so set against anything that sounds like poststructuralist conclusions.

A skeptical reader will accuse me of inconsistency here. After all, Spolsky 
is explaining a fairly widely held idea of identity, only now she is saying we have a biological explanation to support that idea, the same kind of thing I criticized in Carroll and Storey. But Spolsky's idea of identity is supported by a wealth of thought and conclusions in our century. For better or worse, poststructuralist conceptions of identity have at least in a general sense become compelling truths. An explanation such as Spolsky's gains persuasive force because it takes into account strong arguments from both sides of the intellectual divide. In any event, here we plainly have an alternative to the hostility that drives Carroll and Storey (neither mentions Spolsky's book). Given the currency of this explanation of mind, Spolsky's case is convincing and gives us a new way to look at a certain kind of response to literature. We may expect other such studies as other explanations of the nature of mind come along.

But now to turn to our second possible area of relevance: the interpretation of actual literary texts. If evolutionary psychology and cognitive science are really to matter in literary studies, then they will have to do more than say what literature is. In other words, if a theory does not produce much of interest in the way of practice, then however true the theory may be, it just will not make much difference to most literary scholars, who after all have a bottom-line concern with interpreting specific texts. Both Carroll and Storey offer interpretations of specific texts that, while interesting enough in some ways, do not really need and at times do not even make use of the science that supposedly brings about the claims. Spolsky's book does make direct use of the science in such a way as to bring about a new understanding, but as mentioned above, she depends on a study of literary criticism rather than of literature to make her points. Modularity theory for her is "a systematic basis for describing change in literary interpretation" (9). Studying the history of critical positions acts as a reader-response project in which "different styles of criticism can be seen as evidence of the existence of distinguishable, if interdependent modes of knowledge, originating in distinguishable if interdependent modules of the mind" (10). Thus, Spolsky's work relates to literary interpretation only by implication.

As an example of work that does make use of cognitive science and does interpret specific literary (and other) texts, we may consider in more detail Mark Turner's The Literary Mind (1996). ${ }^{4}$ We have referred above to the importance Turner assigns to narrative in relation to cognition. This book is

4. To be fair to Carroll and Storey, we should note that Turner's book is unencumbered by anti-poststructuralist rhetoric only because he had already had his say in Reading Minds (1991). But unlike Carroll and Storey, Turner does take into account (cf. especially 109-15) the theories of mind (Edelman's and Damasio's) that in many ways seem to reinforce what thinkers such as Lacan have said. 
his best exploration of that idea. In a way his ideas about narrative stand in relation to particular narratives as Chomsky's generative grammar stands in relation to particular examples of grammar. Turner lays out a set of fundamental "image schemas" that are deducible from very basic human orientations to the material world and that are backed up to one degree or another by brain research and linguistics $(22-25)$. These schemas are fundamental units of narrative or, more exactly, of parable. The basic parable he defines as the projection of a source story or space onto a target story or space in such a way that new understanding occurs. Parable is the model of human thought and perception. ${ }^{5}$ With image schemas and parable in hand, he then turns to a variety of literary examples and shows how actions, imagery, character, and the like are understandable as elaborations of these most basic elements. ${ }^{6}$ This produces some insightful interpretations, particularly when he turns to the idea of "blended spaces." These latter are examples of parable in which, rather than the "direct, one-way, and positive" projection found in the basic model, we also find a recursive projection from the target back to the source (6o). The concept of parable blending carries him into some subtle and detailed interpretations, as, for example, his three-page explication of two lines from Shakespeare's King fohn (64-66). ${ }^{7}$ Yet he, like Carroll and Storey before him, has not always seemed to need the science in order to make the interpretations he produces. In the explication of the Shakespeare passage, he concludes that the "scene is profoundly ironic, exactly because in the blended space there is an ironic tension between the image schemas" (66). But in fact he has only mentioned one image schema just in passing (64), and the rest of his interpretation is simply very fine New Critical close reading. Now in this book Turner aims primarily to demonstrate the way in which cognition happens analogously to literary representation, so in a certain sense he is using litera-

5. Turner's project here does with parable very much what Mark Johnson (1987) does with metaphor and, in a way, what his own earlier work (1991) had done with metaphor.

6. In addition to Johnson 1987, a related treatment may be found in Gibbs 1994 .

7. Like Spolsky, Turner also keeps in mind the currently dominant explanations of how the mind works. Parable is his chosen type of narrative because of its overtly multiple meanings. Parable is never taken at some singular face value. Rather, it "typically distributes meaning over many spaces. The aggregate meaning resides in no one of them, but rather in the array of spaces and in their connections. ... Meanings, in this way, are not mental objects bounded in conceptual places but rather complex operations of projecting, blending and integrating over multiple spaces" (85-86). This decentralization, this lack of a final core of meaning, is analogous in a general way to the explanations of mind found in, for example, Bernard Baars, Paul Churchland, Jerry Fodor, Daniel Dennett, Ray Jackendoff, and, it must be said, much of poststructuralism. As mentioned above (n. 6), Turner has shared Carroll and Storey's animosity for poststructuralism, but if he sees the relationship between this cognitive-science version of consciousness and the poststructuralist one, he never admits it. 
ture to explain cognition rather than using cognition to explain literature. What in fact seems to happen is that he uses each to explain the other. But in any event, he himself includes interpretations (which is good), and we may legitimately expect the cognitive-scientific and the literary claims to need each other.

Another possible objection to Turner's ideas might be that from a certain perspective they can be seen as reductive. As Sabine Gross writes in her extended review of Turner's earlier book, Reading Minds, it begins to appear that it is "the task of cognitive studies to analyze . . conceptual patterns and thus establish the meaning of literature" in a kind of rationalist cookiecutter fashion. This "imposition of cognitive discourse will in fact abolish or reduce the distinguishing features of literary discourse. In other words, tailoring the object of inquiry to the mode of inquiry entails refashioning the former in ways that fail to do it justice" (282). The cognitive-scientific kind of analysis can become what amounts to "a problem-solving exercise dominated by abstract, rational intellectual analysis" (294). Though to me what Turner does with literature in The Literary Mind is superior to what he does in Reading Minds, for many literary scholars Gross's charges would apply equally to the more recent book.

With this criticism we approach our final questions about the current and possible future situation of cognitive science and literary study, and we return to questions left not quite settled above. Can there be the kind of expansive, fruitful crossover between cognitive science, evolutionary psychology, and literary criticism that seems so likely? There is no simple answer. On the one hand, both fields will be in some ways irresistible in the way that scientific explanation is so often irresistible. How can empirically established, scientific claims about the biology and psychology of reading, writing, and responding have no bearing on the discipline whose meat and potatoes is reading, writing, and responding? And yet can we expect cognitive science and evolutionary psychology to become for the literary criticism of the twenty-first century what psychoanalysis has been for the twentieth? If this does not come to pass, it will likely be precisely because cognitive science and evolutionary psychology, unlike psychoanalysis, are bona fide empirical sciences. This fact presents both practical and theoretical problems. The practical problem we have seen above with Carroll, Storey, Simon, and Pinker. Adequate scientific knowledge is simply outside the expertise of all but a minority of literary scholars. The literary in literary study is simply outside the expertise of all but a minority of cognitive scientists and evolutionary psychologists. Few scholars will have time or inclination to learn the other field sufficiently to challenge what is most scientific about the one or most literary about the other, and as a result it is hard to imagine a large, general audience either way. 
Theoretically, and again taking up the extreme skeptical position, the problem has to do with what might seem an unsurpassable either/or. To put the case oversimplistically (which is to say in the extreme), either cognitive science and evolutionary psychology are unacceptably reductive, or they are not really relevant to any but a very specialized branch of literary study. We may usefully discuss this idea in terms that have been an integral part of literary studies for a while now: sameness and difference. Both cognitive science and evolutionary psychology depend on empirical research to discover sameness, universals, facts that are independent of history (except over very long spans) and culture. Through rigorous laboratory work both fields are providing and will continue to provide scientific explanations of how and why human beings in general respond to literature and how and why human beings in general create literature as they do. So when we bring cognitive science or evolutionary psychology to the study of literature, we must be taking off from some use of these universals. Given this fact, there will likely be two main kinds of application of those universals to literary study: proving that the universals are actually present in literature (which will become the cookie-cutter approach), and then explaining variation from the usual case, that is, accounting for difference. As far as I can tell, there are two most general options in accounting for difference. The first is to explain variation by other scientific arguments. For instance, if we are told that hearing or reading a certain phoneme induces a specifiable and predictable physical response, or even that hearing or reading a certain pattern of concepts (as in narrative) induces a physical response, then we could explain variations from this defined response by searching out the psychological or physiological cause. This will be a turn into at least a de facto determinism and, in any case, will fail to interest most literary scholars.

The other way to account for difference is to seek out causes not arising from physiological or cognitive-psychological universals, which is to say, causes arising in the broadest sense from culture. If we are not to stay entirely with arguments from the empirical sciences, then we will necessarily come back around to culture - that is, language, ideology, politics, history - if we are to account for difference. For example, we might ask: If cognitive science defines thought itself as like conventional narrative form, then what are we to make of willful violations of conventional narrative form? What are we to make of the evolution of narrative as a genre? In fact, the question of historical change in specific cultural productions and actions will continually be a problem for an approach that is ultimately bound to physiological universals. Human biology changes over time, but only very, very slowly. One can translate evolution to the level of concepts, as Richard Dawkins (1976) has most famously done, but at some point the concepts 
seem to take on a qualitatively separate kind of existence. Though the biological model may be used to explain how concepts evolve, this is not the same as ascribing the evolution of concepts to physiological processes. So, to stay with cognitive science for a moment, given that this area of study is defining a certain class of physiological facts based on research with contemporary human beings, what does it mean that at least many contemporary human beings create and respond to significantly different kinds of literature than earlier human beings did? Will the answers to this kind of question change what we know about science, or about literature? In short, variations from scientific universals that will make a difference to literary scholars will have to be explained by some form of cultural process; otherwise criticism is a form of biology or empirical psychology, and neither of these will, for most, reveal literary truth. And if this is the case, then to what extent are cognitive science and evolutionary psychology really relevant to literary study?

Having taken up the ultraskeptical stance, I will end with what I take to be a model that answers as successfully as possible the questions I have been asking with respect to the use of cognitive science in the interpretation of an actual literary text: Mary Crane's essay "Male Pregnancy and Cognitive Permeability in Measure for Measure" (1998). Crane, more directly and persuasively than any of the writers we have mentioned so far, addresses the problems of positing an ultimately empirical-scientific basis for literary interpretation in the context of the reigning relativist paradigms. She has enough confidence in herself and in the intrinsic merit of her interdisciplinary approach that she does not have to destroy what will inevitably be her opposition. Thus, rather than simply casting out Foucault and New Historical interpretation, she makes this more judicious claim: "Cognitive theory suggests that, while discourse indisputably shapes our experience and knowledge of the body, embodiment also exerts a reciprocal shaping influence on discourse" (271). Now as we have seen, other writers in these areas typically leave room for this dialectical relation between signs and reality, but Crane actually brings it into her interpretation. She takes up one of Lakoff's fundamental cognitive schemas - "the body as a container with an interior, and exterior, and variously permeable boundaries" (279) and explains how Renaissance humoral theory was a particular historical cultural manifestation of that schema. First, she says that "Shakespeare's experience of embodiment would . . . have been shaped by his culture's dominant theory of physiology." In other words, humoral theory was a discursive or ideological formation producing certain kinds of subjective experience that fit together with other ideologies (such as gender, class, state power, etc.) of the time. But a cognitively oriented approach, she writes, 
argues that humoral theory's particular narratives about the body as a container are built on subsymbolic experiences of embodiment (which give rise to the concept of containment) and that its hierarchizing constructs are so easily assimilable to "external" hierarchies [ideology] because those hierarchies are themselves ultimately built on embodied experiences. Thus the representations of embodiment in a play such as Measure for Measure reflect not only how discourse shapes the body in accordance with dominant cultural formations but also how those very formations and mechanisms of control are literally built on the body. The question becomes, then, not to what extent the play exerts a normativizing force in the formation of early modern subjects but rather in what ways conditions of embodiment are imagined as contributing to the creation of cultural norms. $(278-79)$

Having made the case for the general cognitive importance of a specific set of elements - clustered primarily around the ideas of containment, permeability, and pregnancy - she then turns to a close reading of the text in order to show what these elements come to mean thematically, given the story and characters at hand. The terms from human cognitive architecture require her to look at certain very specific kinds of evidence - such as "images and words that cluster, in radial categories, around spatial concepts, such as agency or containment" (274) - and to interpret that evidence in ways that stand out as distinctly different from other approaches to the text. After discussing in detail this set of elements in relation to various concepts of power in the play, she concludes that

Measure for Measure ... offers a representation of early modern power much more complicated than a state that merely posits an unruly but permeable subject, then penetrates it with language in order to control it. Rather, the play seems to suggest, there is no escape from penetration and contamination, which are properties of the human body, brain, and language systems. Cognitive theory helps us to see this permeability as reflecting the complex, multiple, and reciprocal ways in which the body and language produce each other. The play also suggests that figures of authority, in the process of trying to penetrate subjects, are themselves penetrated, contaminated, changed, impressed, and made productive.

(291)

Whatever the reader may think of the actual interpretation (and of course there will always be disagreement in this respect), there is a strong sense that this essay needs the cognitive-scientific concepts to make its case, and that a significantly different meaning of the text as a whole emerges for that reason.

Thus, Crane avoids the charge of failing to offer anything significantly different from other approaches and goes at least some way toward making the science relevant without being reductive. Avoiding as much as possible the latter charge will be crucial if this new interdisciplinarity is to appeal 
to any but a narrowly specialist audience. An approach such as Crane's does not simply show that cognitive universals are present: she shows what it means that they are present in just this way in just this text as both a cause and an effect of specific cultural processes. She relates the discovery of a cognitive or evolutionary universal to a particular instance of history or culture or genre or individual psychology, and so on, as a means to explain some other, nonscientific meaning of the text(s).

This said, it must be admitted outright that Crane remains subject to the primary attack from poststructuralist skepticism. The idea of the subsymbolic or presymbolic can appear only as a form of Platonic essentialism, as the positing of a kind of magical foundational element that is outside of history and culture. A given writer may, wisely, try to qualify her or his position by stressing the affective relationship between culture and cognitive architecture; but still, the very knowledge of that architecture can only appear to us through discourse; therefore, the architecture itself is ultimately a function of discourse. Psychoanalytic, especially Lacanian, theory has been as successful as it has because it takes just this - the primacy of language, culture, discourse - as its grounding assumption. At any rate, from the skeptical position, the charge of essentialism can always be made.

But of course the situation is an impasse. For those who would aim skepticism back at the relativists, the question can always be asked: once you have posited discourse or culture as the productive forces in human life, then, unless discourse or culture are themselves Platonic essences, they must have something upon which to act. If the relativist concedes that the human animal is that upon which these forces act, then the next question is: what is the nature of that animal? A tabula rasa? An empty vessel? Has it no intrinsic (or essential) qualities at all? Is it produced magically out of nothing by discourse? If the relativist skeptic admits any intrinsic, prediscursive qualities, she or he has just opened the door to arguments such as Lakoff's, Turner's, and Crane's.

I see no way for either side entirely to overcome its particular logical limit. Being hyperskeptical in either direction will always generate questions that cannot be adequately answered. And with this realization we have arrived back where we started: neither relativism nor essentialism can simply eliminate the other's position. And neither relativism nor essentialism can feel completely solid about their claims as long as the other side asks the unanswerable questions. ${ }^{8}$ What then? Well, first we may say that the findings of cognitive science and evolutionary psychology have already 
been seriously and positively affected by the relativistic paradigms that have thrived during the decades in which the two fields have come into their own. The thinking and conclusions in a book such as The Adapted Mind, for instance, would not be what they are without the antagonism (implicit or explicit) of relativist skepticism. That skepticism has forced the writers there to think about the nature and implications of their own work in a critical light that goes beyond the usual critical awareness of someone working in an empirical-scientific discipline. This has made their arguments stronger in the sense that they take into account a much larger audience. The same is clearly true of work such as Mary Crane's.

Now it may well be time for poststructuralist critical positions to take seriously the skepticism from the other side. We could say that since the sixties, much of literary interpretation has thrown the bulk of its energies into discovering difference. This has necessarily and healthily brought about a relative displacement of certain very fundamental concepts of sameness. But of course sameness is the constitutive Other without which difference cannot exist. Discovering difference cannot destroy sameness; it can only recast that sameness in a new way. If it seemed that interpretation before Lacan, Foucault, Derrida, and similar thinkers was too blindly devoted to discovering and fortifying a certain sameness, interpretation after these three may have become overzealous in the opposite direction. But overzealous or not, this enterprise has had a considerable success. Perhaps the generic question to be asked now is: How does difference operate, given the kinds of sameness that have been established by cognitive science and evolutionary psychology?

\section{References}

Adams, Frederick

1994 "Simon Says," Stanford Humanities Review 4. Available on-line at www.stanford.edu/ group/SHR/4-1/text/adams.commentary.html.

Baars, Bernard J. 1988 A Cognitive Theory of Consciousness (Cambridge: Cambridge University Press).

Barkow, Jerome, Leda Cosmides, and John Tooby, eds. 1992 The Adapted Mind: Evolutionary Psychology and the Generation of Culture (New York: Oxford University Press).

Brooks, Peter 1985 Reading for the Plot: Design and Intention in Narrative (New York: Vintage).

Bruner, Jerome 1990 Acts of Meaning (Cambridge: Harvard University Press).

Carroll, Joseph 1995 Evolution and Literary Theory (Columbia: University of Missouri Press).

Churchland, Paul 1995 The Engine of Reason, the Seat of the Soul (Cambridge: MIT Press). 
Crane, Mary Thomas

1998 "Male Pregnancy and Cognitive Permeability in Measure for Measure," Shakespeare Quarterly 49(3): 269-92.

Crane, Mary Thomas, and Alan Richardson

1999 "Literary Studies and Cognitive Science: Toward a New Interdisciplinarity," Mosaic 32(2): 123-40.

Culler, Jonathan

1981 The Pursuit of Signs: Semiotics, Literature, Deconstruction (Ithaca, NY: Cornell University Press).

Dawkins, Richard

1976 The Selfish Gene (Oxford: Oxford University Press).

Dennett, Daniel

1991 Consciousness Explained (Boston: Little, Brown).

Easterlin, Nancy

1999 “Making Knowledge: Bioepistemology and the Foundations of Literary Theory," Mosaic 32(1): 131-47.

Fodor, Jerry

1983 The Modularity of Mind: An Essay on Faculty Psychology (Cambridge: MIT Press).

Gibbs, Raymond W., Jr.

1994 The Poetics of Mind: Figurative Thought, Language, and Understanding (Cambridge: Cambridge University Press).

Gross, Sabine

1997 "Cognitive Readings; or, the Disappearance of Literature in the Mind," Poetics Today 18: $271-95$.

Herman, David

1999 "Parables of Narrative Imagining," diacritics 29: 20-36.

Jackendoff, Ray

1987 Consciousness and the Computational Mind (Cambridge: MIT Press).

Jackson, Tony

1994 The Subject of Modernism: Narrative Alterations in the Fiction of Eliot, Conrad, Woolf, and Foyce (Ann Arbor: University of Michigan Press).

1995 "Nihilism, Relativism, and Literary Theory," SubStance 24: 29-48.

Johnson, Mark

1987 The Body in the Mind (Chicago: University of Chicago Press).

Kaul, Suvir

1994 “' Inverted TS,' or How Not to Build Bridges between the 'Two Cultures': A Polemical

Response," Stanford Humanities Review 4. Available on-line at www.stanford.edu/group/

SHR/4-1/text/kaul.commentary.html.

Kristeva, Julia

1986 "Revolution in Poetic Language," in The Kristeva Reader, edited by Toril Moi, 89-136

(New York: Columbia University Press).

Lakoff, George, and Mark Turner

1989 More than Cool Reason: A Field Guide to Poetic Metaphor (Chicago: University of Chicago Press).

Miers, Paul

1992 "The Other Side of Representation: Critical Theory and the New Cognitivism," Modern Language Notes 107(5): 950-75.

Pinker, Steven

1994 The Language Instinct (New York: HarperCollins).

1997 How the Mind Works (New York: Norton).

Polkinghorne, Donald

1988 Narrative Knowing and the Human Sciences (Albany: State University of New York Press). 
Popper, Karl

1985 Popper Selections, edited by David Miller (Princeton, NJ: Princeton University Press). Prince, Gerald 1981 "Introduction to the Study of the Narratee," in Reader Response Criticism, edited by Jane Tompkins, 7-25 (Baltimore, MD: Johns Hopkins University Press).

Rabinowitz, Peter

1977 "Truth in Fiction: A Critical Examination of Audiences," Critical Inquiry 4: 121-41.

Rorty, Richard

1989 Contingency, Irony, and Solidarity (Cambridge: Cambridge University Press).

Schank, Roger, and Robert Abelson

1977 Scripts, Plans, Goals, and Understanding (Hillsdale, NJ: Lawrence Erlbaum Associates). Spolsky, Ellen

1993 Gaps in Nature: Literary Interpretation and the Modular Mind (Albany: State University of New York Press).

Storey, Robert

1996 Mimesis and the Human Animal: On the Biogenetic Foundations of Literary Representation

(Evanston, IL: Northwestern University Press).

Turner, Mark

1991 Reading Minds: The Study of English in the Age of Cognitive Science (Princeton, NJ: Princeton

University Press).

1996 The Literary Mind (New York: Oxford University Press). 